

\title{
Towards improved quantitative analysis using surface-enhanced Raman scattering incorporating internal isotope labelling $†$
}

\author{
Abdu Subaihi, ${ }^{a}$ Yun Xu, (D) a Howbeer Muhamadali, ${ }^{a}$ Shaun T. Mutter, ${ }^{\text {ab }}$ \\ Ewan W. Blanch, ${ }^{C}$ David I. Ellis (iD a and Royston Goodacre (D) *a
}

Raman spectroscopy has attracted considerable interest during the past two decades as a vibrational technique used for the molecular characterisation of different molecules. Whilst the Raman eff ect is known to be generally weak, it is also known that this can be greatly improved using surface-enhanced Raman scattering (SERS). Indeed, in recent years, the power of SERS for rapid identification and quantification of target analytes in a wide range of applications has been repeatedly demonstrated in multiple studies. Moreover, the application of SERS in combination with an isotopically labelled compound (ILC), as an internal standard, has also very recently shown promising results for quantitative SERS measurements, by improving both its accuracy and precision. This is due to the ${ }^{12} \mathrm{C}$ and ${ }^{13} \mathrm{C}$ or ${ }^{1} \mathrm{H}$ and ${ }^{2} \mathrm{H}$ (D) having similar physicochemical properties. The use of these internal standards results in the reduction of any influences due to the number of nanoparticles within the analysis zone and fluctuations in laser fluence. Thus, in this study we have employed SERS for quantitative detection of tryptophan (Trp) and caffeine. These have been chosen because Trp is readily available as the deuterated form and caffeine is available in both ${ }^{12} \mathrm{C}$ and ${ }^{13} \mathrm{C}$. Quantum chemical calculations based on density functional theory (DFT) have been utilized to determine the vibrational characteristics of the target analytes. For SERS analysis incorporating isotopologues of tryptophan three independent experiments were conducted with three diff erent batches of nanoparticles over a 12 month period; our results show that the use of this internal standard improves quantification of this target molecule. In particular for the independent test sets (i.e., samples not used in quantitative partial least squares regression (PLSR) model construction) we observed improvements in the linearity for test set predictions, as well as lower errors in test set predictions, when isotope internal standards were used during SERS for both deuterated tryptophan as well as ${ }^{13} \mathrm{C}$ caff eine. This work is an extension of and a natural progression from our earlier studies. By exploring additional analytes of interest, allowing for the assessment of the different types of stable isotopes as internal standards, and demonstrating the transfer/robustness of isotopologues for use with SERS, we believe this approach could be readily extended to other biologically-relevant compounds.

\section{Introduction}

Raman spectroscopy is a powerful technique providing biochemical ngerprints of the sample under investigation. ${ }^{1,2}$ The Raman eff ect has generally been associated with weak signals, which can be said to have been the driving force behind the continued development of Raman techniques such as resonance Raman spectroscopy (RRS) or surface-enhanced

aSchool of Chemistry, Manchester Institute of Biotechnology, University of Manchester, 131 Princess Street, Manchester, M1 7DN, UK. E-mail: roy.goodacre@manchester.ac. uk; Tel: +44 (0)1613064480

${ }^{b}$ Department of Chemistry, Cardiff University, Cardiff, Wales, UK

${ }^{\mathrm{c} S}$ chool of Science, RMIT, GPO Box 2476, Melbourne, Victoria 3001, Australia
Raman scattering (SERS) to improve the signal response of conventional Raman scattering. Thus, issues concerning uo-rescence, low sensitivity and reproducibility are being overcome by these new techniques and approaches. It is generally accepted that SERS improves the Raman signal through the adsorption (or very close proximity) of species onto a roughened metal substrate. ${ }^{3-5}$ There is a perception within the literature that SERS suffers from poor reproducibility (as reviewed in ref. 6). For colloidal-based SERS, this may be due to the number of nanoparticles within the collection volume and unavoidable uctuations in laser power ( uence). In this study isotopic labelling (IL) strategies are employed to improve this quantita-tive method further in terms of efficiency, reproducibility and linearity. The IL approach is based on the addition of a known constant quantity of an isotopically-labelled analog (iso-topologue or spike) of the target analyte to the original sample 
as an internal standard, prior to any further treatment. As the isotopolog is chemically identical (with the obvious exception of the isotope substitution) the IL-SERS approach combines high sensitivity and molecular speci city with the asset of reliability, accuracy and repeatability through quantitative analysis. Although isotope labelling mass spectrometry (ILMS) has been applied in diff erent areas of analytical chemistry, as a quanti-tative detection method to provide high accuracy reference measurements, ${ }^{7-9}$ compared to IL-SERS this approach requires complex sample preparation, while the instrumentation cost is also relatively high. The IL approach has also been carried out by Zakel and Stosch to develop a quantitative method for measuring creatinine as a biomarker in human serum. ${ }^{10}$ This study concluded that the combination of SERS and IL had proved to be a valuable approach for clinical diagnostic measurements.

Tryptophan (Trp) is an essential amino acid required for the biosynthesis of proteins and functions as a precursor of active substances such as serotonin. ${ }^{11}$ However, a reduction in the level of Trp may cause pellagra, which is niacin-Trp de ciency disease with symptoms of dermatitis, diarrhea, dementia, and mood-alterations. The change in brain Trp levels also leads to changes in brain serotonin synthesis. ${ }^{12}$ A recent study has also shown signi cant gender-speci c changes in Trp levels concomitant with aging. ${ }^{13}$ Trp is comprised of two active func-tional groups; carboxylic $(-\mathrm{COOH})$ and amino $\left(-\mathrm{NH}_{2}\right)$, the interaction of carboxyl and amino groups on SERS has been investigated previously, as strong vibrational enhancement is generated from these two groups. ${ }^{14}$ Several studies have also investigated the SERS activity and the interaction of diff erent metal surfaces with amino acids. ${ }^{15-17}$ These studies have also demonstrated that Trp molecules may interact with the surface through $\mathrm{COO}$ and $\mathrm{NH}_{2}$ groups.

Caff eine (1,3,7-trimethylxanthine), is a typical alkaloid related to the purine alkaloids, which is also a natural compound widely found in coff ee beans, tea leaves, cola nuts and several plants, it is also added to so drinks as a avouring agent ${ }^{18}$ and many pharmaceutical products. The international Olympic Committee (IOC) has classi ed caff eine as an abuse drug when present in urine at level of $>12 \mathrm{mg}$ $\mathrm{mL}{ }^{1} \cdot{ }^{19,20}$ The overconsumption of caffeine can lead to adverse eff ects on human health such as increase of gastric-acid secretion, heart disease (cardiac arrhythmia), kidney malfunction and disorder of the nervous system. ${ }^{21}$ Therefore, accurate quantitative anal-ysis of drugs is important in order to establish long-term abuse of illicit compounds, as well as establish accurate drug dosing for legal therapeutics. However, analysing the levels of drugs found in human bio uids requires methods that are highly sensitive and reproducible, as well as the additional potential for portability and point-of-care diagnostics.

Detection and quanti cation of Trp and caffeine has improved through the use of multiple analytical techniques such as chromatography coupled with mass spectrometry. ${ }^{19,22,23}$ Whilst these methods generate a high level of qualitative and quantitative results, they are not, to date, ${ }^{24}$ generally considered eld portable, and require specialist operatives as well incurring a high analysis cost. By contrast, recent studies have demonstrated the application of SERS for the detection and quanti cation of Trp and caff eine with high levels of sensitivity and reproducibility. ${ }^{25,26}$ Alharbi et al. concluded that SERS can be used to identify long-term abuse of illicit materials as well as determine accurate drug dosing for legal therapeutics. Furthermore, Chen and colleagues reported the interaction of caffeine molecules with different colloids at various concen-trations. ${ }^{27}$ Finally, in a very recent study, we have also demon-strated the effect of isotopic labelling (using deuterated codeine) for improved quantitative detection of codeine in human plasma using SERS. ${ }^{28}$

The current work is a follow on from the mentioned work above, that was recently published in Analyst, ${ }^{28}$ where in the present study we aim to investigate stable isotopes of hydrogen and carbon: the isotopolog for Trp was deuterated (Trp-d5) and for caff eine all three methyl groups were replaced with ${ }^{13} \mathrm{CH}_{3}$. In this study we show that SERS can be successfully developed as a highly quantitative method for the detection of Trp and caffeine via adoption of the IL-SERS principle combined with multivariate statistical analysis techniques. In this study we also perform repeat measurements where the laser power is 'degraded' to show transfer/robustness of the isotopologue concept. Our results clearly demonstrate the potential applica-tions of this strategy as a quantitative approach for different compounds, which could provide increased accuracy and precision and which have the potential to bene $t$ a wide range of analytical elds.

\section{Experimental}

\section{Chemicals}

Gold(III) chloride trihydrate $(99.9 \%)$, trisodium citrate, silver nitrate (99.9\%), high purity Trp (99\%) and caff eine were purchased from Sigma Aldrich (Sigma-Aldrich, Dorset, UK). Isotopically labelled Trp-d5 (98\%) and caffeine (trimethyl- ${ }^{13} \mathrm{C}_{3}, 99 \%$ ) were purchased from Cambridge Isotope Laboratories, Inc. (Tewksbury, MA, USA). Chemicals were used as supplied and all solvents used were of analytical grade.

\section{Nanoparticle synthesis and characterisation}

The Turkevich method was used to synthesise gold nano-particles. ${ }^{29}$ A $100 \mathrm{~mL}$ volume of $50 \mathrm{mg} \mathrm{HAuCl} 4$ solution was added to $850 \mathrm{~mL}$ of boiling water, and while the solution was vigorously stirred $50 \mathrm{~mL}$ of trisodium citrate was added. A er 30 min the solution had changed to a deep red colour and was le to cool.

The Lee and Meisel citrate reduction method was used to produce silver nanoparticles, ${ }^{30}$ and to remove any trace metals from the glassware, aqua regia (nitric acid : hydrochloric acid $(1: 3$, v/v)) was used for cleaning. The asks were washed using cleaning detergent and rinsed with water prior to being oven dried at $50 \mathrm{C}$ for $25 \mathrm{~min}$. A er dissolving $\mathrm{AgNO}_{3}(90 \mathrm{mg})$ in $500 \mathrm{~mL}$ of water, this was heated to boiling point. Then $1 \%$ trisodium citrate $(10 \mathrm{~mL})$ solution was added, and stirred gently at a steady boil for $15 \mathrm{~min}$. When the solution started to change 
to a milky green colour, the end point of the reaction was reached.

See ESI† for more details of UV-vis and SEM instrumenta-tion. UV-vis spectrophotometry was used to characterize the nanoparticles size distribution to allow comparison of several batches and data generated were similar to those data collected previously by our group. ${ }^{31-33}$ The $1_{\max }$ of nanoparticles were identi ed to be 534, 563 and $527 \mathrm{~nm}$ for gold and silver respectively (Fig. S1a and b†). Moreover, scanning electron microscopy (SEM) was used to assess the nanoparticles in terms of their morphology (Fig. S1c and $\mathrm{d} \dagger$ ), and the average size of the nanoparticles for AuNP and AgNP was found to be $1612 \mathrm{~nm}$ and $8326 \mathrm{~nm}$ respectively.

\section{Stock solutions and internal standard preparation}

Aqueous stock solutions of natural isotopes containing Trp and caffeine $(10 \mathrm{~mL}$ each), along with the correspondingly labelled internal standard compounds, Trp- $\mathrm{d}_{5}$ or ${ }^{13} \mathrm{C}$ caff eine, were prepared in water. Mixture dilutions of the unlabelled compounds were prepared over a range of concentrations for Trp and caff eine from 0-90 mM. The nal concentrations of the internal standards spiked into unlabelled samples were $20 \mathrm{mM}$. Calibration curves for each of the analytes were constructed using the above mixtures.

\section{Colloidal-based SERS in solution}

Spectra were collected using a DeltaNu Advantage benchtop Raman spectrometer (DeltaNu, Laramie, WY, USA), equipped with a 633 $\mathrm{nm} \mathrm{HeNe}$ laser with a power output of $3 \mathrm{~mW}$ on the sample. Spectra were collected for $30 \mathrm{~s}$ over a range of $200-3500 \mathrm{~cm}{ }^{1}$. Samples were placed in an $8 \mathrm{~mm}$ diameter glass vial and subjected to laser irradiation once loaded into the sample cell attachment. The instrument was calibrated using a poly-styrene internal standard as supplied by the instrument manufacturer to determine the ideal distance from the laser to the glass vial. SERS sample preparation and analysis was per-formed as follows: $200 \mathrm{~mL}$ of colloid was added to a glass vial followed by $200 \mathrm{~mL}$ of Trp - Trp-d5 or caff eine $-{ }^{13} \mathrm{C}$ caff eine, along with $50 \mathrm{~mL}$ aggregating agent. The vial was then vortexed for $2 \mathrm{~s}$ and inserted into the sample cell attachment where a spectrum was acquired immediately.

\section{Data analysis}

The molecular geometry and vibrational frequency calculations were carried out using the Gaussian 09 package. ${ }^{34}$ Structures were constructed by hand and optimised using density function theory (DFT) with the B3LYP functional ${ }^{35,36}$ utilising the cc-pVTZ basis set. ${ }^{37}$ Vibrational frequencies and Raman intensities were calculated at the same level of theory for geometry optimisation. The assignments of Raman bands for Trp and caff eine with their labelled molecules were based on gas phase calculations. ${ }^{38}$ Visualisation of vibrational modes and generation of Raman spectra was carried out using Gaussview $5 .^{39}$

For chemometric analysis Raman spectra were analysed using MATLAB so ware R2013a (The Math Works Inc, Natick, USA). First, a set of univariate regression models were established by the regression of the integrated areas of the discriminatory peaks of interest, against the known concen-tration of the target analytes (Trp and caff eine). A further set of univariate regression models was then established by replacing the integrated peak areas of the analytes with the peak area ratios of the analytes to the internal standards (analyte/internal standard).

Finally, a series of multivariate regression models were also constructed using partial least square regression (PLSR). ${ }^{40,41}$ These three models used the entire Raman spectra for quanti-cation of the two analytes with, and without, the Trp- $\mathrm{d}_{5}$ or ${ }^{13} \mathrm{C}$ caff eine isotopes as internal standards. The generated PLSR models were validated by a projection approach, ${ }^{42,43}$ where $60 \%$ of the data were used as the training set to generate the model (concentrations 0, 20, 40, 50, 70, and $90 \mathrm{mM}$ Trp or caffeine) while the remaining $40 \%$ were projected as a test set $(10,30,60$ and $80 \mathrm{mM})$ for validation purposes. A er calibration gures of merit were calculated for the models based on errors: root-mean-square error of cross validation (RMSECV) for the training set and root-mean-square error of prediction (RMSEP) for the test set. In addition, coefficients of determination were calculated for both the training sets $\left(\mathrm{R}^{2}\right)$ and test $\operatorname{set}\left(Q^{2}\right)$.

\section{Results and discussion}

The application of IL coupled with conventional Raman spectroscopy has focussed considerable attention on the classi ca-tion ${ }^{44}$ and quanti cation of bacterial metabolism, ${ }^{45}$ as well as being utilised for the characterization of various bioprocesses. ${ }^{46}$ This study is an extension and natural progression of our earlier study, where we focused only on the deuterated molecule codeine spiked into the human plasma. ${ }^{28}$ In addition, our previous study only used a single batch of nanoparticles, whereas the current study is investigating the effects of isotope standards using either deuterium (tryptophan) or the ${ }^{13} \mathrm{C}$ labelled molecule caffeine, and also includes multiple batches of SERS substrates which were run on diff erent days (a year apart).

Preliminary Raman analysis (see ESI† for more details of the conventional Raman measurements) of Trp and Trp-d5 and ${ }^{12} \mathrm{C}$ and ${ }^{13} \mathrm{C}$ caff eine were carried out to identify vibrational spectral shi $\mathrm{s}$ due to changes in reduced mass of various functional groups containing either D $\left({ }^{2} \mathrm{H}\right)$ or ${ }^{13} \mathrm{C}$. Comparison of the Raman spectra of labelled and unlabelled Trp (Fig. S2a†) revealed the main bands affected by the labelling process to be peaks at $844,1050,1189$ and $1597 \mathrm{~cm}^{1}$, corresponding to phenyl ring $\mathrm{CD}$ bending, indole ring $\mathrm{CD}(\mathrm{NH})$ bending, phenyl ring breathing and indole ring $\mathrm{CD}(\mathrm{NH})$ bending respectively. ${ }^{47}$ These band assignments have been based on DFT calculations and Table 1 contains a full list of all other detected peaks and their corresponding band assignments. A similar approach was also employed to identify and compare the diff erences between Raman spectra of labelled and unlabelled caff eine (Fig. S2b†). The high intense peak at $561 \mathrm{~cm}^{1}$ is attributed to $\mathrm{CH}$ bending, $\mathrm{CH}_{3} \mathrm{sym}$. bending and $\mathrm{CH}_{3}$ rocking vibrations which displayed a noticeable shi in the Raman spectrum of labelled caff eine to $548 \mathrm{~cm}^{1}$. All other detected peaks and their respective 
Table 1 Experimental and calculated Raman and SERS bands (in $\mathrm{cm}^{1}$ ) with vibrational assignments for Trp and Trp-d5

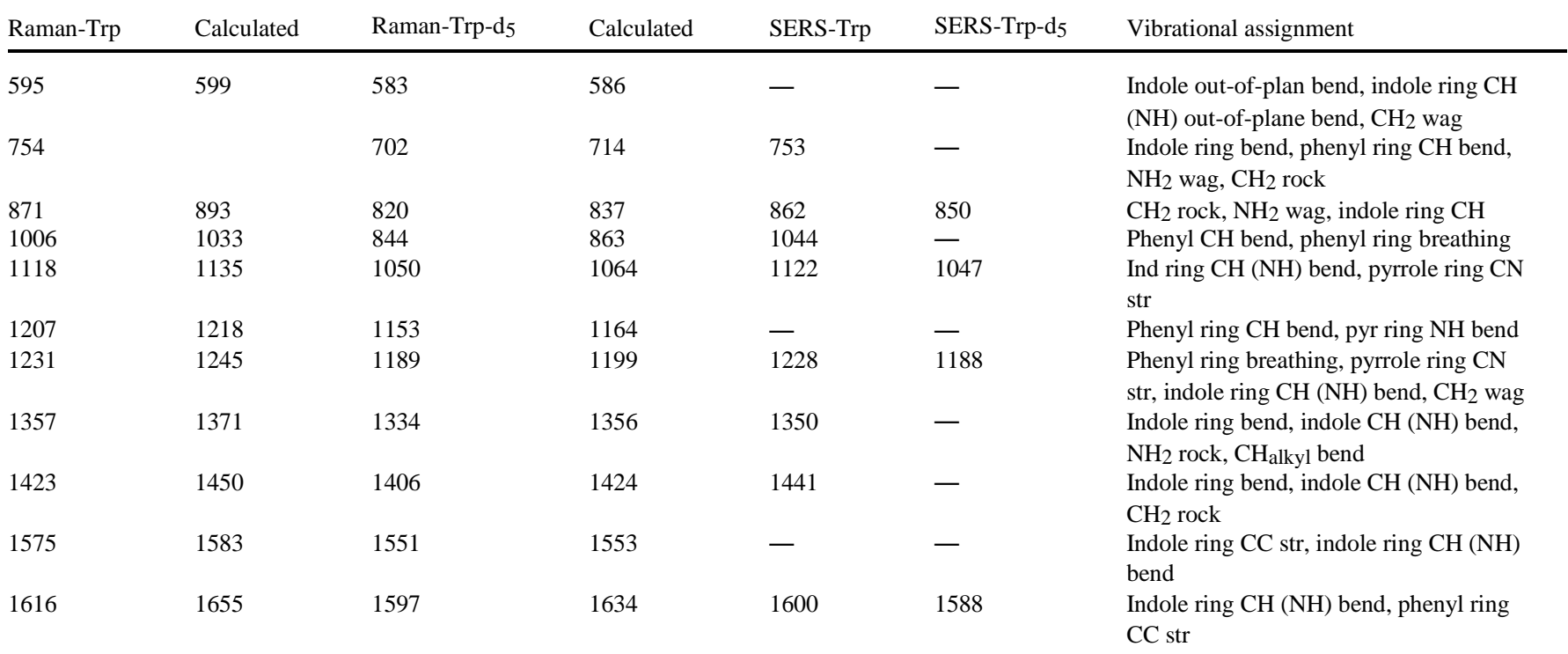

vibrational assignments are listed in Table 2. ${ }^{27,48,49}$ As caff eine is only labelled through the $\mathrm{CH}_{3}$ functional groups, the Raman peaks related to the indole ring were not signi cantly affected by the labelling process. However, this could perhaps be investigated in more detail by labelling the nitrogen atoms of the ring in future studies.

Optimisation of SERS parameters is generally necessary to reach the optimal conditions and reproducibility and achieve signal enhancement. $^{6,50}$ It is well known that the sensitivity of SERS depends on the binding of molecules with a surface as well as the presence of an aggregation agent. ${ }^{51}$ Therefore, in this study four different colloids including silver citrate (SC), gold citrate (GC), hydroxylamine silver citrate (HASC) and sodium borohydridereduced silver (SBRS), have been examined and compared. In general, batch-to-batch variation and reproduc-ibility of SERS is a key discussion point within the Raman community. Therefore, multiple batches of nanoparticles (n $1 / 4$

3) were prepared and used separately over a 12 month period, in order to investigate the efficiency of the isotopic labelling approach towards the quantitative detection of the analyte of

Table 2 Experimental and calculated Raman and SERS bands (in $\mathrm{cm}^{1}$ ) with vibrational assignments of unlabelled and ${ }^{13} \mathrm{C}$ labelled caff eine

\begin{tabular}{|c|c|c|c|c|c|c|}
\hline $\begin{array}{l}\text { Raman } \\
\text { unlabelled caff }\end{array}$ & Calculated & $\begin{array}{l}\text { Raman } \\
\text { labelled caff }\end{array}$ & Calculated & $\begin{array}{l}\text { SERS } \\
\text { unlabelled caff }\end{array}$ & $\begin{array}{l}\text { SERS } \\
\text { labelled caff }\end{array}$ & Vibrational assignment \\
\hline 447 & 445 & 445 & 441 & & & $\mathrm{CH}_{3}$ sym. bend $+\mathrm{CH}_{3}$ rock \\
\hline 487 & 483 & 482 & 482 & 506 & 496 & $\begin{array}{l}\text { Imidazole ring def }+\mathrm{O}] \mathrm{C}-\mathrm{N} \text { def }+\mathrm{CH} \\
\text { bend }\end{array}$ \\
\hline 561 & 555 & 548 & 546 & & & $\mathrm{CH}$ bend $+\mathrm{CH}_{3}$ sym. bend $+\mathrm{CH}_{3}$ rock \\
\hline 643 & 647 & 643 & 642 & 646 & 646 & $\begin{array}{l}\text { Imidazole ring def }+\mathrm{O}] \mathrm{C}-\mathrm{N} \text { def }+\mathrm{CH}_{3} \\
\text { sym. bend }\end{array}$ \\
\hline 740 & 751 & 737 & 744 & 746 & & $\begin{array}{l}\text { Imidazole ring def }+\mathrm{CH}_{3} \text { sym. bend }+ \\
\mathrm{CH}_{3} \text { rock }\end{array}$ \\
\hline 803 & 813 & 803 & 811 & & & Imidazole ring def $+\mathrm{C}] \mathrm{O}$ def $+\mathrm{CH}_{3}$ rock \\
\hline 931 & 939 & 926 & 932 & 940 & & Imidazole $+\mathrm{CH}_{3}$ rock \\
\hline 1026 & 1032 & 1021 & 1028 & 1006 & & $\mathrm{CH}_{3}$ rock $+\mathrm{C}-\mathrm{N}$ str $+\mathrm{C}-\mathrm{N}$ bend \\
\hline 1079 & 1088 & 1073 & 1081 & 1075 & & $\mathrm{H}-\mathrm{C}] \mathrm{N}$ bend \\
\hline 1140 & 1155 & 1128 & 1143 & 1169 & 1131 & $\mathrm{~N}-\mathrm{CH}_{3}$ asym. bend \\
\hline 1241 & 1265 & 1239 & 1259 & 1250 & 1250 & $\mathrm{C}-\mathrm{N}$ str \\
\hline 1289 & 1299 & 1287 & 1297 & 1328 & 1325 & $\mathrm{C}_{2}-\mathrm{N}_{3}$ sym. str $+\mathrm{CH}_{3}$ rock \\
\hline 1332 & 1354 & 1328 & 1348 & & & Imidazole trigonal ring str \\
\hline 1365 & 1383 & 1359 & 1379 & 1372 & 1363 & $\mathrm{C}-\mathrm{N}$ str $+\mathrm{CH}_{3}$ sym. bend \\
\hline 1412 & 1451 & 1406 & 1438 & 1416 & 1413 & $\mathrm{CH}_{3}$ sym. bend $+\mathrm{C}_{14}-\mathrm{N}_{7}$ sym. str \\
\hline 1556 & 1571 & 1556 & 1570 & 1584 & 1575 & $\mathrm{CH}_{3}$ sym. bend $+\mathrm{CH}_{3}$ bend $+\mathrm{C}-\mathrm{N}$ str \\
\hline 1603 & 1619 & 1603 & 1617 & & & $\begin{array}{l}\mathrm{C}] \mathrm{C} \text { sym. str }+\mathrm{C}-\mathrm{N} \text { sym. str }+\mathrm{CH}_{3} \text { sym. } \\
\text { bend }\end{array}$ \\
\hline 1657 & 1670 & 1657 & 1668 & 1681 & & Out-of-phase C]O str + C]C sym. str \\
\hline 1700 & 1722 & 1700 & 1720 & & & In-phase C]O str \\
\hline
\end{tabular}


interest. The results indicated that gold citrate and silver citrate provided the highest reproducibility and stability for Trp (data not shown) and caffeine (Fig. S3†) respectively. Moreover, potassium nitrate, sodium chloride and potassium sulfate solutions $(0.5 \mathrm{M})$ were also examined in order to identify the optimal aggregating agent for the analytes used.

The highest SERS intensity for Trp was observed when $\mathrm{KNO}_{3}$ was added to Au-citrate (Fig. S4†), which was used for all further studies. Furthermore, in order to establish the in uence of the aggregation time, Trp peak area at $1122 \mathrm{~cm}^{1}$ (C-H vibration) both with and without the IL internal standard was monitored as a function of time and recorded through 78 time-points for $39 \mathrm{~min}$. We observed a rapid initial aggregation a er addition of the salt $\left(\mathrm{KNO}_{3}\right)$ which gave the optimum SERS response
(Fig. S5a†). Moreover, mixtures of Trp with Trp-d5 remained unchanged for a period of time 15 min compared to Trp alone, which supports our assumption that the isotopologue associates with the metal nanoparticle surface with the same efficiently as its unlabelled equivalent. The intensity is approx-imately half because the concentration of $\operatorname{Trp}$ has been diluted to $50 \%$ when spiked with the isotope (CH/CD) (Fig. S5b†).

SERS spectra of unlabelled and labelled Trp obtained using gold colloids are displayed in (Fig. 1a). These spectra show successful binding of Trp and Trp- $\mathrm{d}_{5}$ to the surface and are similar to other previous studies that investigated unlabelled Trp. ${ }^{25,52}$ It is clear that some of the bands are shi ed to lower wavenumbers due to the presence of the heavier isotopes of Trp- $\mathrm{d}_{5}$. Peaks at 1122, 1228 and $1600 \mathrm{~cm}^{1}$, assigned to phenyl
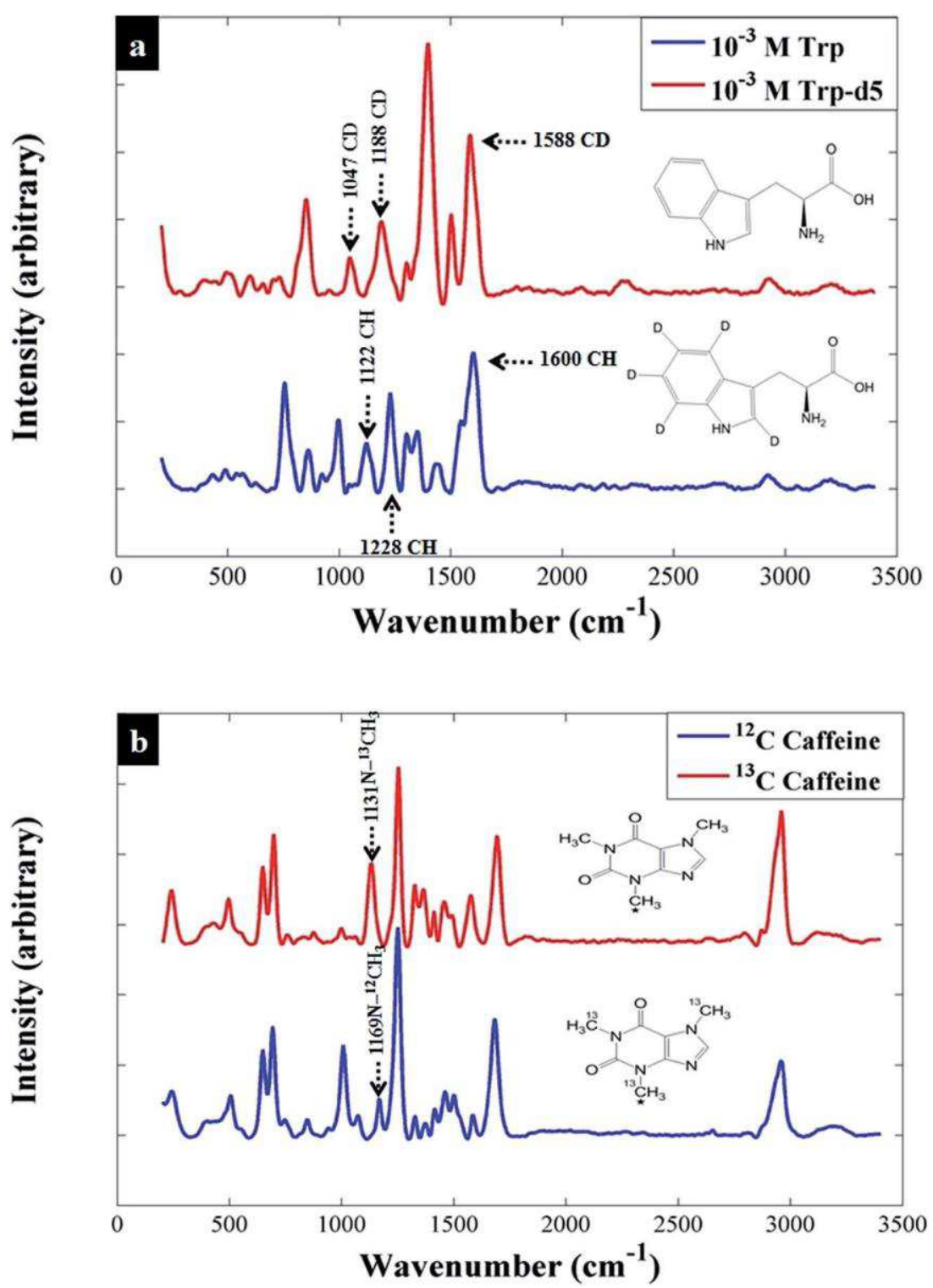

Fig. 1 Baseline-corrected SERS spectra of unlabelled (blue) and labelled (red) analytes: (a) Trp and Trp-d5 with gold citrate and $0.5 \mathrm{M}$ KNO 3 aggregation agent; (b) ${ }^{12} \mathrm{C}$ 'unlabelled' caff eine and ${ }^{13} \mathrm{C}$ labelled caff eine with silver citrate and $1 \mathrm{M} \mathrm{NaCl}$ aggregation agent. Key vibrations are highlighted (see Tables 1 and 2 for band assignments). In addition, the structures of tryptophan and caff eine are shown along with the position of the $D\left({ }^{2} H\right)$ or ${ }^{13} \mathrm{C}$ isotope label. 

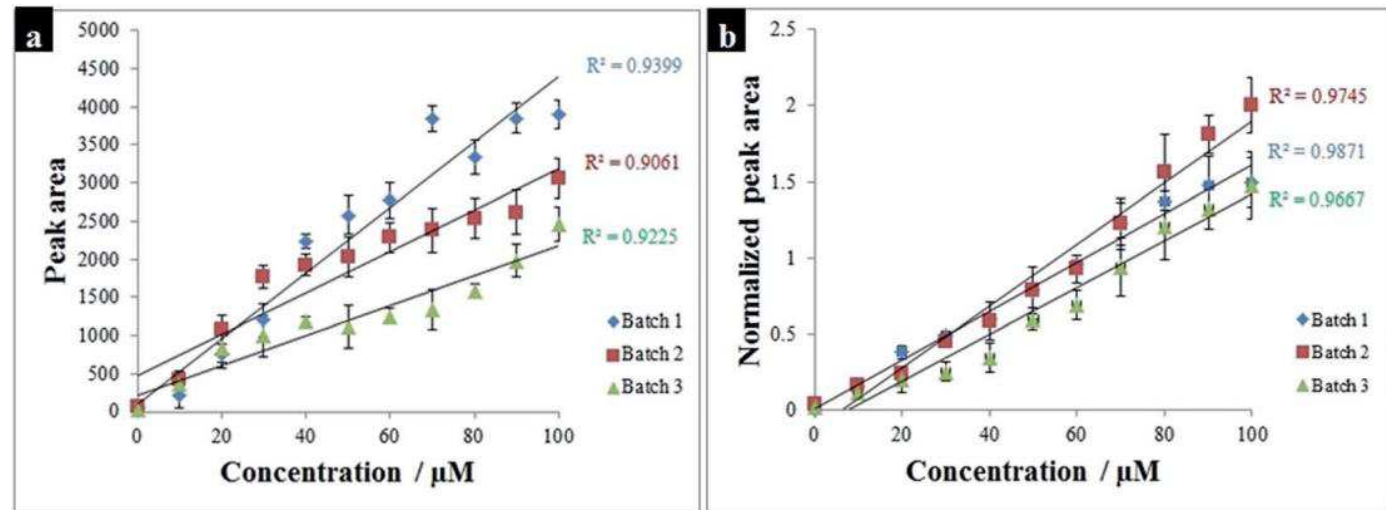

Fig. 2 Plots of characteristic peak for Trp: (a) represents peak area of Trp at $1122 \mathrm{~cm}{ }^{1}$ versus Trp concentration; (b) shows normalized peak area using the IL internal standard at $1047 \mathrm{~cm}^{1}$ for correction. The error bars denote standard deviation of the mean of five measurements.

$\mathrm{CH}$ bending vibration, phenol ring breathing and indole ring $\mathrm{CH}(\mathrm{NH})$ bending, exhibited a shi to lower wavenumbers at 1047,1188 and $1588 \mathrm{~cm}^{1}$. These band assignments are supported by our DFT results, which con rm these peak assignments. A list of the main bands and their corresponding assignments are presented in Table $1 .{ }^{16,47,53}$
According to Fig. 1b, the most signi cant SERS spectral band in uenced by ${ }^{13} \mathrm{C}$ labelling of caff eine is the peak at $1169 \mathrm{~cm}{ }^{1}$, assigned to the $\mathrm{N}_{-}{ }^{13} \mathrm{CH}_{3}$ asymmetric bending vibration, which shi $\mathrm{s}$ to $1131 \mathrm{~cm}{ }^{1}{ }^{54-56}$ Once again DFT calculations were used in order to obtain the vibrational assignments, and these band assignments for unlabelled and labelled caff eine are provided
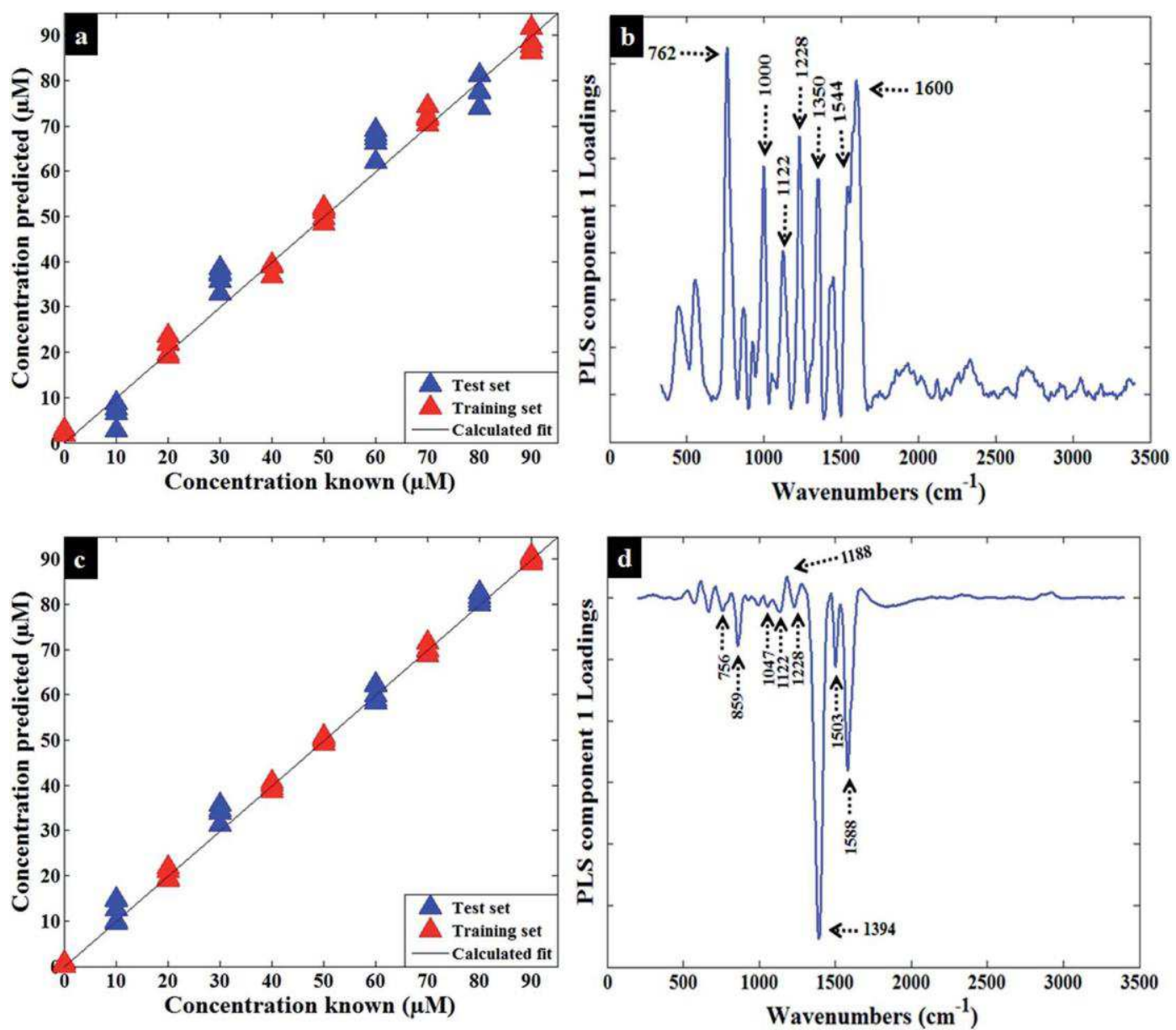

Fig. 3 Representative typical PLSR plots from batch 1 of predicted concentration versus known concentrations of (a) Trp and (c) mixtures of Trp + Trp-d5. Also shown are the corresponding PLSR loading plots for (b) Trp alone and (d) after including the Trp-d5 isotopic labelled analyte. 
in Table 2. Calibration curves were plotted to establish the linearity of analyte specific peak areas as a function of Trp (Fig. 2a) and caffeine (Fig. S6a†) concentrations. In addition, the ratios of normalised peak areas of the analytes to their IL internal standards were also plotted versus the concentration range (Fig. $2 b$ and S6b $†$ ). The linear ranges of these plots were used to calculate the limit of detection (LOD) of Trp and caffeine to be $3.86 \mathrm{mM}$ and $0.1 \mathrm{mM}$ respectively. Noticeably, there is an off set in the normal calibrations (Fig. 2a), which could be due to batch-to-batch variation from repeat productions of the NPs, as well as differences in the size of nanoparticles, their concen-trations, and the relative enhancement which may result in poor linearity and accuracy.

However, normalization of the peak of interest at $1122 \mathrm{~cm}^{1}$ to the IL internal standard at $1047 \mathrm{~cm}^{1}$ have clearly overcome this issue and minimised this off set. On closer inspection of the corrections a er the use of the isotopologue it can be observed that the three calculated best $t$ lines are not wholly congruent. It is possible that within the separate nanoparticle batches that this is a result of slight differences in orientation of the tryp-tophan molecules on the three surface types, due to the diff erent geometries of the colloid. This means that for each batch of colloid a new calibration curve would need to be generated and this is usual when any detector is calibrated for absolute quanti cation. We do see that the UV-visible absor-bance spectra of all three batches of Au colloid are indeed different (Fig. S1a†). This may then lead to minimal changes in the relative ratios of the $\mathrm{C}-\mathrm{H}$ and $\mathrm{C}-\mathrm{D}$ vibrations in tryptophan (from the substitution of ${ }^{1} \mathrm{H}$ with ${ }^{2} \mathrm{H}$ on the indole ring in this molecule) that are observed between the batches. As discussed above, the IL internal standard is used as a reference to compensate for experimental errors and as can be seen in Fig. $2 b$ and S6b, $\uparrow$ there was an improvement in both accuracy and reproducibility upon normalisation to these IL internal standards. In particular, the linearity of the signal with respect to analyte concentration was improved as the regression results increased from $R^{2} 1 / 40.9399$ to $R^{2} 1 / 40.9871$ for Trp from batch 1 (see the regression results of batch 2 and 3 in Fig. 2) and from $R^{2}$

\section{$1 / 40.8394$ to $\mathrm{R}^{2} 1 / 40.9669$ in caff eine (Fig. S6b†).}

In addition to the univariate linear regression, we also employed multivariate calibration using the quantitative PLSR models, conducted as described previously in the methods
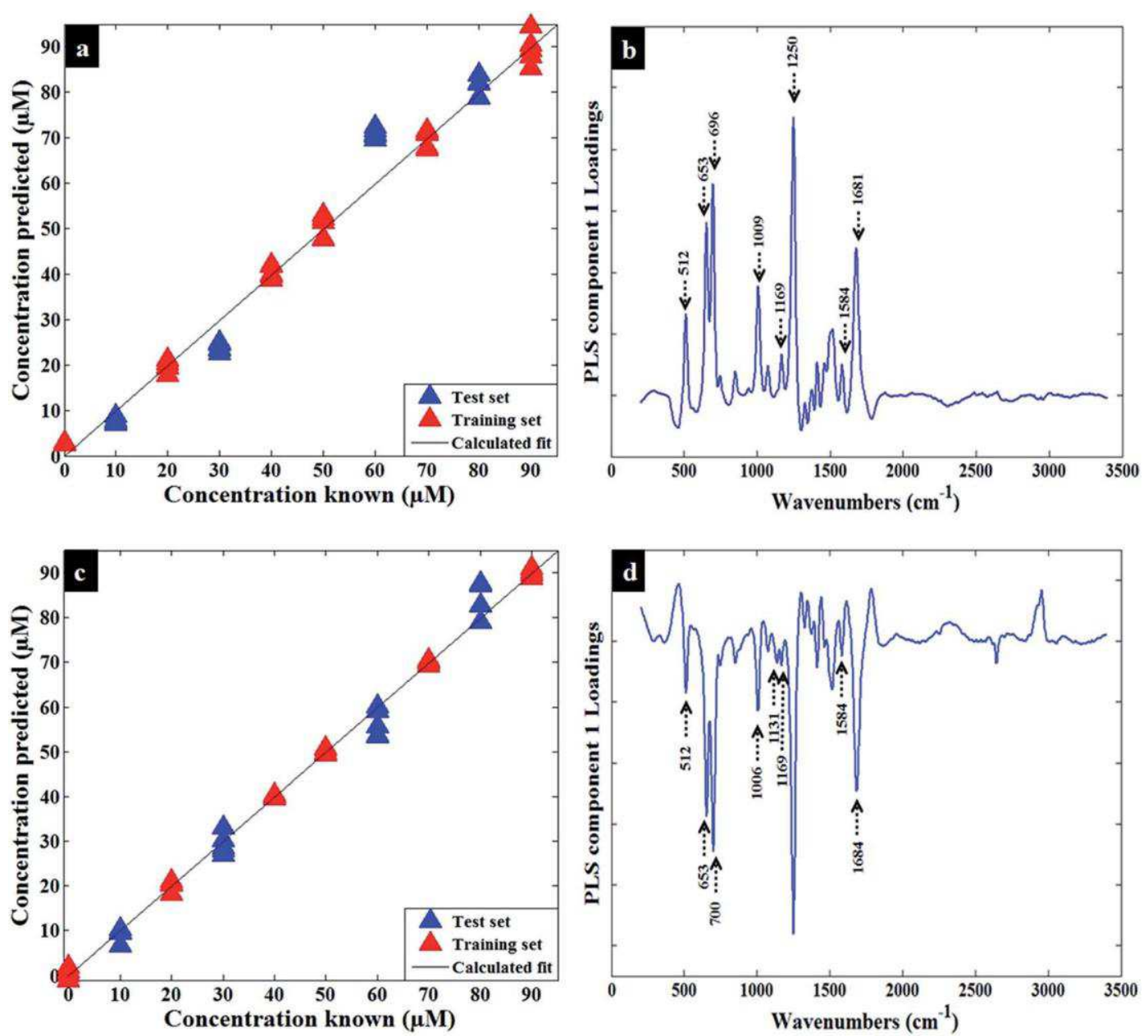

Fig. 4 Representative typical PLSR plots of predicted concentration versus known concentrations of (a) caff eine and (c) mixtures of ${ }^{12} \mathrm{C}$ caff eine $+{ }^{13} \mathrm{C}$ caff eine. Also shown are the corresponding PLSR loading plots for (b) ${ }^{12} \mathrm{C}$ caff eine alone and (d) after including the ${ }^{13} \mathrm{C}$ isotopically labelled caffeine. 
Table 3 Summary of the statistics for prediction of Trp using multiple batches of nanoparticles and caff eine with and without spiking with the isotopically labelled equivalent chemical ${ }^{\mathrm{a}}$



${ }^{\text {a }}$ Factors specify the number of latent variables used in PLSR; RMSEP, root-mean-squared error of prediction (from the test set); RMSECV root-meansquared error of cross validation (from the training set); $\mathrm{R}^{2}$ and $\mathrm{Q}^{2}$ show linearity for the training and test sets predictions, respectively.

section. The PLS models showed improvements via the inclusion of the IL internal standards for the analysis of Trp (Fig. 3a, c, S7a, c, S8a, and $\mathrm{c} \dagger$ ) in batches 1 to 3 respectively, and caff eine (Fig. $4 \mathrm{a}$ and c). Furthermore, the PLS predictions showed good agreement between the predicted concentrations of the target analytes and their known concentrations in general, and again, the models using the data with IL added signi cantly improved the linearity of the test set predictions $\left(\mathrm{Q}^{2}\right)$ of Trp from 0.81 to 0.85 from batch 1 and caff eine from 0.77 to 0.85 , with a decrease in test set errors (RMSEP) from 6.03 to 2.86 for Trp and from 2.08 to 0.11 for caff eine. The comparison between these two analytes using multiple batches of nanoparticles in terms of higher reproducibility and accuracy is detailed in Table 3. Furthermore, the PLS component loadings were plotted to con rm the above ndings, which revealed that the peaks at 1047, 1188 and $1588 \mathrm{~cm}^{1}$ were the most signi - cant variables aff ected by Trp-d5 (Fig. 3b, d, S7b, d, S8b, and d†) from batches 13 respectively, and the band at $1131 \mathrm{~cm}^{1}$ was the peak most distinctly in uenced by ${ }^{13} \mathrm{C}$ caff eine (Fig. $4 \mathrm{~b}$ and $\mathrm{d}$ ).

\section{Conclusions}

This study, which was a natural progression from and extension of our previously published work, has clearly demonstrated the potential application of SERS combined with isotopologues (ILSERS) for the quantitative detection of Trp and caff eine. The unique features of SERS spectra resulting from the added isotopes improved the quanti cation methods based on the ratio of (analyte/IL internal standard) and this was the case for both ${ }^{2} \mathrm{H}$ for tryptophan and ${ }^{13} \mathrm{C}$ for caffeine. The C-D stretch in the tryptophan isotope is clearly identi able and can be used as the internal standard vibration for the $\mathrm{C}-\mathrm{H}$ stretch from non-deuterated tryptophan (i.e. the natural isotope abundance). In order to demonstrate the reproducibility of our approach, we chose to repeat the quantitative analysis of this molecule with three different batches of colloid over a 12 month period. The results reported here clearly demonstrate that this isotopologue improves the level of quanti cation, both from univariate analysis as well as via the multivariate method of PLSR. Thus the application of the IL approach, has clearly improved the accuracy of the PLSR models while minimising errors resulting from batch-to-batch variations of nanoparticles. This approach may also be useful when the SERS band shi s due to the isotopes overlap with other vibrational features in the spectra (which would mean that ratios of bands would be difficult to compute). The recorded Raman and SERS spectra of Trp and caff eine and their labelled compounds were assigned based on literature assignments as well as theoretically modelled spectra from quantum chemical calculations based on density func-tional theory. For our SERS analyses we determined the LODs of Trp and caff eine to be $3.86 \mathrm{mM}$ and 0.1 $\mathrm{mM}$ respectively, with indication of high reproducibility, accuracy and stability of the spectra that forwards IL-SERS as a practicable strategy with potential for various analytical applications. Future studies will be conducted to extend this method for analysis of target determinants present in complex biological samples such as blood, plasma and urine.

\section{Conflicts of interest}

The authors have no conflicts of interest.

\section{Acknowledgements}

A. S. thanks The Saudi Ministry of High Education and Umm alQura University for funding. R. G. is indebted to U.K. BBSRC (Grant BB/L014823/1) for funding for Raman spectroscopy.

\section{References}

1 D. I. Ellis, D. P. Cowcher, L. Ashton, S. O'Hagan and R. Goodacre, Analyst, 2013, 138, 3871.

2 D. I. Ellis and R. Goodacre, Analyst, 2006, 131, 875.

3 M. Moskovits, Rev. Mod. Phys., 1985, 57, 783.

4 M. Fleischmann, P. Hendra and A. McQuillan, Chem. Phys. Lett., 1974, 26, 163.

5 D. L. Jeanmaire and R. P. Van Duyne, J. Electroanal. Chem. Interfacial Electrochem., 1977, 84, 1.

6 H. Fisk, C. Westley, N. J. Turner and R. Goodacre, J. Raman Spectrosc., 2016, 47, 59.

7 C. Phinney, K. E. Murphy, M. J. Welch, P. Ellerbe, S. Long, K. Pratt, S. Schiller, L. Sniegoski, M. Rearick and T. Vetter, Fresenius. J. Anal. Chem., 1998, 361, 71. 
8 L. G. Mackay, C. P. Taylor, R. B. Myors, R. Hearn and B. King, Accredit. Qual. Assur., 2003, 8, 191.

9 M. Aranda and G. Morlock, Rapid Commun. Mass Spectrom., 2007, 21, 1297.

10 S. Zakel, S. Wundrack, G. O'Connor, B. Guttler“ and R. Stosch, J. Raman Spectrosc., 2013, 44, 1246.

11 P. L. Delgado, D. S. Charney, L. H. Price, G. K. Aghajanian, H. Landis and G. R. Heninger, Arch. Gen. Psychiatry, 1990, 47, 411.

12 S. N. Young and M. Leyton, Pharmacol., Biochem. Behav., $2002,71,857$.

13 W. B. Dunn, W. Lin, D. Broadhurst, P. Begley, M. Brown,

E. Zelena, A. A. Vaughan, A. Halsall, N. Harding and

J. D. Knowles, Metabolomics, 2014, 11, 9.

14 C. H. Chuang and Y. T. Chen, J. Raman Spectrosc., 2009, 40, 150.

15 E. Podstawka, Y. Ozaki and L. M. Proniewicz, Appl. Spectrosc., 2005, 59, 1516.

16 S. Stewart and P. Fredericks, Spectrochim. Acta, Part A, 1999, $55,1641$.

17 S. Stewart and P. Fredericks, Spectrochim. Acta, Part A, 1999, $55,1615$.

18 R. R. Griffiths and E. M. Vernotica, Arch. Fam. Med., 2000, 9, 727.

19 M. S. Bispo, M. C. C. Veloso, H. L. C. Pinheiro, R. F. De Oliveira, J. O. N. Reis and J. B. De Andrade, J. Chromatogr. Sci., 2002, 40, 45.

20 J. A. Carrillo and J. Benitez, Clin. Pharmacokinet., 2000, 39, 127.

21 P. J. Green, R. Kirby and J. Suls, Ann. Behav. Med., 1996, 18, 201.

22 R. Bossi and B. H. Bech, Spectroscopy, 2015, 31.

23 W. T. Zhu, A. P. Stevens, K. Dettmer, E. Gottfried, S. Hoves, M. Kreutz, E. Holler, A. B. Canelas, I. Kema and P. J. Oefner, Anal. Bioanal. Chem., 2011, 401, 3249.

24 D. I. Ellis, H. Muhamadali, S. A. Haughey, C. T. Elliott and R. Goodacre, Anal. Methods, 2015, 7, 9401.

25 A. Kandakkathara, I. Utkin and R. Fedosejevs, Appl. Spectrosc., 2011, 65, 507.

26 O. Alharbi, Y. Xu and R. Goodacre, Anal. Bioanal. Chem., 2015, 407, 8253.

27 X. Chen, H. Gu, G. Shen, X. Dong and J. Kang, J. Mol. Struct., 2010, 975, 63.

28 A. Subaihi, H. Muhamadali, S. T. Mutter, E. Blanch, D. I. Ellis and R. Goodacre, Analyst, 2017, 142, 1099.

29 J. Turkevich, P. Stevenson and J. Hillier, Discuss. Faraday Soc., 1951, 11, 55.

30 P. Lee and D. Meisel, J. Phys. Chem., 1982, 86, 3391.

31 S. Mabbott, E. Correa, D. P. Cowcher, J. W. Allwood and

R. Goodacre, Anal. Chem., 2012, 85, 923.

32 C. Westley, Y. Xu, A. J. Carnell, N. J. Turner and R. Goodacre, Anal. Chem., 2016, 88, 5898-5903.

33 W. Cheung, I. T. Shadi, Y. Xu and R. Goodacre, J. Phys. Chem. C, 2010, 114, 7285.

34 M. J. Frisch, G. W. Trucks, H. B. Schlegel, G. E. Scuseria, M. A. Robb, J. R. Cheeseman, G. Scalmani, V. Barone, B. Mennucc, G. A. Petersson, H. Nakatsuji, M. Caricato,
X. Li, H. P. Hratchian, A. F. Izmaylov, J. Bloino, G. Zheng, J. L. Sonnenberg, M. Hada, M. Ehara, K. Toyota, R. Fukuda, J. Hasegawa, M. Ishida, T. Nakajima, Y. Honda, O. Kitao, H. Nakai, T. Vreven, J. A. Montgomery Jr, J. E. Peralta, F. Ogliaro, M. Bearpark, J. J. Heyd, E. Brothers, K. N. Kudin, V. N. Staroverov, R. Kobayashi, J. Normand, K. Raghavachari, A. Rendell, J. C. Burant, S. S. Iyengar, J. Tomasi, M. Cossi, N. Rega, J. M. Millam, M. Klene, J. E. Knox, J. B. Cross, V. Bakken, C. Adamo, J. Jaramillo, R. Gomperts, R. E. Stratmann, O. Yazyev, A. J. Austin, R. Cammi, C. Pomelli, J. W. Ochterski, R. L. Martin, K. Morokuma, V. G. Zakrzewski, G. A. Voth, P. Salvador, J. J. Dannenberg, S. Dapprich, A. D. Daniels,

O. Farkas, J. B. Foresman, J. V. Ortiz, J. Cioslowski and D. J. Fox, Gaussian 09, Gaussian, Inc., Wallingford CT, 2009.

35 A. D. Becke, J. Chem. Phys., 1993, 98, 5648.

36 C. Lee, W. Yang and R. G. Parr, Phys. Rev. B, 1988, 37, 785.

37 T. H. Dunning Jr, J. Chem. Phys., 1989, 90, 1007.

38 S. Miertus and J. Tomasi, Chem. Phys., 1982, 65, 239.

39 R. Dennington, T. Keith and J. Millam, GaussView, version

5.0.8, Semichem Inc., Shawnee Mission, KS, 2009.

40 P. Geladi and B. R. Kowalski, Anal. Chim. Acta, 1986, 185, 1.

41 H. Martens and T. Naes, Multivariate calibration, John Wiley \& Sons, 1992.

42 D. P. Cowcher, Y. Xu and R. Goodacre, Anal. Chem., 2013, 85, 3297.

43 A. Subaihi, L. Almanqur, H. Muhamadali, N. Almasoud,

D. I. Ellis, D. K. Trivedi, K. A. Hollywood, Y. Xu and

R. Goodacre, Anal. Chem., 2016, 88, 10884-10892.

44 H. Muhamadali, D. Weaver, A. Subaihi, N. AlMasoud,

D. Trivedi, D. I. Ellis, D. Linton and R. Goodacre, Analyst, 2016, 141, 111-122.

45 H. Muhamadali, M. Chisanga, A. Subaihi and R. Goodacre, Anal. Chem., 2015, 87, 4578.

46 W. E. Huang, K. Stoecker, R. Griffiths, L. Newbold, H. Daims, A. S. Whiteley and M. Wagner, Environ. Microbiol., 2007, 9, 1878.

47 N. Maiti, S. Thomas, J. A. Jacob, R. Chadha, T. Mukherjee and S. Kapoor, J. Colloid Interface Sci., 2012, 380, 141.

48 M. De Matas, H. Edwards, E. Lawson, L. Shields and P. York, J. Mol. Struct., 1998, 440, 97.

49 M. Baranska and L. M. Proniewicz, Vib. Spectrosc., 2008, 48, 153.

50 R. M. Jarvis, W. Rowe, N. R. Yaffe, R. O'Connor,

J. D. Knowles, E. W. Blanch and R. Goodacre, Anal. Bioanal. Chem., 2010, 397, 1893.

51 N. R. Yaffe and E. W. Blanch, Vib. Spectrosc., 2008, 48, 196.

52 A. Aliaga, I. Osorio-Rom’an, P. Leyton, C. Garrido,

J. Carcamo, C. Caniulef, F. Celis, F. D’1az, E. Clavijo and

J. G'omez-Jeria, J. Raman Spectrosc., 2009, 40, 164.

53 G. Socrates, Infrared and Raman characteristic group frequencies: tables and charts, John Wiley \& Sons, 2004.

54 J. Kang, H. Gu, L. Zhong, Y. Hu and F. Liu, Spectrochim. Acta, Part A, 2011, 78, 757.

55 I. Pavel, A. Szeghalmi, D. Moigno, S. C^^1nt a and W. Kiefer, Biopolymers, 2003, 72, 25.

56 W. Wang, W. Zhang, Y. Duan, Y. Jiang, L. Zhang, B. Zhao and P. Tu, Spectrochim. Acta, Part A, 2013, 115, 57. 